\title{
What we're reading
}

Reviewing the two most read articles in each of the eight issues the Editorial Collective has published to date tells an interesting story about what our readership are attracted to at this particular time in social work. In her commentary piece for the journal, Linda Briskman argued "that we do not need to merely revitalise the radical but to name it, proudly and loudly" (Briskman, 2017, p. 133). And while the articles we mention below are the top reads (from the journal system's "view" statistics) in each issue, there are many other contributions that address professional, policy and practice research themes weaving in critical analysis and hopes for transformational change.

Radical and critical perspectives in social work have attracted many readers in the journal in the first two years since we moved to an online, open access format. We are pleased that our journal is reflecting locally the Aotearoa New Zealand contribution to international debates both through research (Keddell \& Hyslop, 2018) and critical policy scholarship (Keddell, 2016). A common theme of much local research and policy critique is that policies of targeting, use of systems data and investment discourse require an articulate and evidenced social work response which is anti-oppressive, promotes social justice, and which places the families and communities we work with at the centre of social work practice.

Ian Hyslop started the trend in 2016 with "Where to social work in a brave new Aotearoa" raising issues which have continued to be addressed in practice and policy pieces alike (Hyslop, 2016) where the themes of neoliberal impacts on social work practice are described and critiqued. In the same year, Mike O'Brien (2016) provided a strong analysis of the significant policy change built around three key terms; investment, vulnerable, and outcomes.
Mike notes that these are not neutral descriptors but rather shaped in "critical ways by the neoliberal framework which informs them" (p. 1). Critical analysis of policy contributes to shaping practice that is politically aware and cognisant of how neoliberal policies impact on the families, whānau and communities in which we practise. Hannah Blumhardt, Fourth World UK, and Anna Gupta's article "Radical practice in a risk-averse environment: Learning from ATD Fourth World UK" notes that child protection in many settings can be "inflexible, top-down ... coupled with an atmosphere of policing, control and disregard for the impact of poverty" (Blumhardt, ADT Fourth Work \& Gupta, 2017, p. 19). Blumhardt et al. argue that these features of state systems constrain social workers and families alike, eroding relationships. The ATD Fourth World approach described in the article promotes genuine strengths-based practice that relies on nuanced understandings of poverty, a commitment to advance families' wishes, and trusting relationships grounded in human dignity and commonality.

Steve Rogowski (2017) provides our first "classic text revisited" series review with his thoughts on the impact of Bailey and Brake's Radical Social Work. Closer to home, Alastair Russell, a social worker who works for Auckland Action Against Poverty, contributed "Competent solidarity: The alternative for professional social work" setting out some important principles for effective advocacy working with people battling systems for housing and benefit rights.

Sawyers (2016) proposes a social work response to the Ministry of Social Development's Community Investment Strategy social policy. Sawyers utilises Beddoe and Maidment's (2009) critical
AOTEAROA

NEW ZEALAND SOCIAL WORK 30(1), 1-6. 
intersections model to critically examine the Productivity Commission's (2015) policy-framing report "More Effective Social Services." The social investment approach is discussed in relation to service user perspectives, critical social theory, social justice and the role of the social work profession.

Continuing with a focus on critical social policy, Liz Beddoe and Eileen Joy in their 2017 article, "Questioning the uncritical acceptance of neuroscience in child and family policy and practice: A review of challenges to the current doxa," explore the spectre of prevention science, particularly neuroscience, which is used to justify state interventions into the lives of families considered to be "vulnerable" or "troubled." Beddoe and Joy conducted an examination of trends in child welfare and protection policy and argue that much of the current use of prevention science fits the dogma of the Western neoliberal agenda. They argue that the invocation of science in the struggle to reduce child maltreatment may be reassuring to politicians, policy developers and practitioners alike but a critical analysis suggests that it minimises other knowledge from social science findings about poverty, racism and inequalities.

The profession of social work itself features in the next tranche of "top two" articles from 2016-2017, with topics including becoming bicultural, social work roles and identities and use of social media. Petro Booysen and Barbara Staniforth (2017), report on research on counselling as an element of social work in "Counselling in social work: A legitimate role?" Booysen and Staniforth note that social work roles are often seen to sit on a continuum between macro and micro perspectives. This qualitative study explores the legitimate function of counselling in social work in Aotearoa New Zealand finding that social workers regularly use counselling skills. They argue that rigid boundaries between the two professions can have adverse effects for clients at times when multi-skilled professionals are needed.
Rebecca Giles' article (2016) reports on social workers' perceptions of multi-disciplinary team (MDT) work in a major regional hospital in Aotearoa New Zealand. Giles found that social workers considered that effective, well-facilitated MDTs enhanced important non-medical aspects of patient care in order to improve patient outcomes. However, where the facilitation of MDTs was poor, and where social work and patient concerns with wider non-medical issues was devalued, outcomes included confusion and distress for patients and a failure to coordinate effective plans for discharge. Giles argues that over-emphasis on the "discourse of the patient as a 'site of disease', and a preoccupation with the management of risk" (p. 25) devalues holistic, patientcentred perspectives.

A personal reflective narrative by Heidi Crawford (2016) recounts the experiences of the author's journey as a Pākehā towards bicultural practice. Developing competence in bicultural practice holds many challenges for Pākehā social workers including contemplating their own journey of understanding and growth towards addressing guilt and shame. Crawford shares her discovery of loss of identity as Pākehā and encourages other Pākehā to connect with who has gone before them in an attempt to understand self and understand others and move towards compassion and hope.

Elizabeth Hobbs and Nikki Evans (2017) note that the fight for recognition of social work's professional status has been influenced by multiple factors including negative public perceptions and conflict within the profession revealing diverse ideas about practice standards and accountability polarising opinions. Several identity themes emerged during the 83 interviews with social workers: the influence of statutory child protection on social work identity, professional marginalisation in multidisciplinary teams and the potential impact of mandatory registration of social workers. The authors noted that many participants seemed to experience levels 
of self-stigma and recommended further research in this area.

The history of social work professionalisation in Aotearoa New Zealand prior to the 1990s is the focus of Sonya Hunt's first of two articles $(2016,2017)$ which provide a historical overview of the struggle for professional status. In this first article, subtitled "the dream" Hunt considers the various theoretical and historical dimensions and interests that have featured in the journey of professionalisation of social work in Aotearoa New Zealand. Based on a review of the literature, the article outlines a definition of social work, and different concepts and approaches to professionalisation while contextualising the journey through our brief history, from early forms of welfare precolonisation up until the early 1990s.

A further article focusing on the profession itself is provided by Deb Stanfield, Liz Beddoe, Neil Ballantyne, Simon Lowe, and Nicole Renata in "Critical conversations: Social workers' perceptions of the use of a closed Facebook group as a participatory professional space" (2017). Stanfield et al. note, as a starting point, that social media, by providing networked public spaces offer many possibilities for social workers to engage in discussion and develop their professional networks. In Aotearoa New Zealand, the development of a closed professional Facebook group provided an ideal opportunity to explore social workers' perceptions of the potential of such a space for professional deliberation and debate. The study reports both benefits and challenges, the nature of online behaviour and the limitations and strengths of Facebook as a place to promote robust professional dialogue on social issues.

The final group of "top two" articles present new knowledge for practice in social work. In the first of two Australian research contributions, Heather Fraser, Nik Taylor and Tania Signal describe a project that explored what an Australian RSPCA Humane Education Program might teach social workers about the benefits of interspecies empathy for young people. Fraser et al. (2017) note that, while empathy rightfully receives much attention in social work practice, interspecies empathy has yet to be included. The programme was offered mostly to newly arrived refugee and migrant young people living in the outer suburbs of Melbourne, whose prior experiences of and/or attitudes towards animals may not have been positive. Participants self-reported increases in empathy for animals, including those they had previously feared or shunned.

Shirley-Ann Chinnery's article, "Social work's fingerprint on the evolution of attachment theory," reminds readers that social work practice knowledge was influential in the evolution of attachment theory. Chinnery notes that the social work skills upon which early attachment knowledge was premised remain important to contemporary care practice. Chinnery outlines attachment theory and its practical relevance for care practice assessment and describes the watershed moments in its development with particular emphasis on social work's connections to this development. The article also reviews the concept of the internal working model and its value for distinguishing emotional differences in an adult's relational biography. Deep understanding of this theory is likely to be instrumental to achieving better outcomes in foster care.

And finally, from the 2016 issue, in "Creativity and innovation in social work practice and research," Michele Jarldorn explored the use of photography in an Australian social work research project which aimed to promote social change. Jarldorn used photovoice to better understand the postrelease experiences of women within the context of rising prison populations and high rates of recidivism. Participants were given a single-use camera and asked, "if you had 15 minutes with a policy maker or politician, what would you want to tell them about your experience?" Later, the 
participants' narratives were combined with the photographs and used to create an art exhibition to raise awareness. This is a fascinating example of participatory action; arts-based methods such as photovoice can be positive and empowering of both participants and researchers.

So, to sum up the first two years produced an interesting and eclectic range of articles. We are very grateful to our authors for their imagination and skill and to the many anonymous reviewers who give their time to strengthen the articles we carry and thus improve the standing of the journal.

What we would like to see more of? We would like to receive more empirical articles on how social work is practised, (comparing the reality to the rhetoric); robust programme evaluations, and articles that will inform readers about innovations especially in bicultural and multicultural practice. We are also keen to expand the published policy analysis as the new Aotearoa New Zealand government begins to bed in and operationalise social policy changes in numerous fields where social work makes a contribution.

We encourage readers to consider submission - we accept full-length articles, short research briefs, viewpoint pieces and we are keen to discuss book reviews and longer "classic" book reviews.

Information for prospective authors can be found at https: / / anzswjournal.nz/anzsw / information/authors

\section{The first issue of 2018}

The articles in this new issue reflect the broad research interests of social workers and social policy analysts. The articles do not share one particular focus but display a range of methodologies and topics.

Bethli Wainwright, Marilyn Waring, Shirley Julich, Polly Yeung, and Jenny Green lead off this first issue for 2018 with an important report on transplant recipients' perceptions and experiences after the first three years and discusses how they re-established aspects of everyday life as they adapted to their new normal to achieve quality of life. This qualitative study avoided the usual quantitative health-related QOL measure seeking a less rigid method which could capture the lived experiences of liver transplant recipients.

The next two articles have social workers in schools in focus. Liz Beddoe, Irene de Haan and Eileen Joy's article reports from a qualitative study of school-based social workers who were asked to describe two things that, from their perspective, would improve schools' responses to child abuse and neglect. Beddoe et al. report that school social workers advocated for improved training and better support for teachers on child abuse concerns, a more holistic approach to child wellbeing in schools; and enhanced understanding of child welfare systems. The authors note that school social workers use their relationship skills and knowledge to bridge gaps between schools and statutory services and believe they can do more.

In a second, "research brief," article, Beddoe and de Haan report further on the same project with a focus on a theme of variation in making formal notifications of concerns to the statutory agency in schools. This issue was strongly identified in the analysis, reflecting previous local and international research. Stigma associated with child abuse was also reported as a factor in school staff attitudes towards reporting. School social workers advocated for joint education for social workers and teachers to ensure a common knowledge base and better interprofessional work.

Shajimon Peter and Lynne Soon-Chean Park contribute a very different article on the usefulness of critical realism (CR) in social work research. This research brief is the outcome of a research methodology literature review undertaken by two doctoral students who employ $\mathrm{CR}$ perspectives. 
Peter and Park discuss how CR can help bridge the gap between objectivism and subjectivism in research. They argue that CR offers an alternative that social work researchers have long been searching for: to engage meaningfully in studies that examine perceived realities at the empirical level and the causal mechanisms that lie behind them.

Howard Randal discusses the two contrasting agendas evident when statutory registration for social workers in Aotearoa New Zealand was introduced in 2003 - that of the professional association and that of the government. Randal draws on a longitudinal research study of the aspirations for statutory registration held by a sample of members of the association. Analysis demonstrates that the profession, although aspiring to holding some role in statutory registration, also retained concerns about its implications. In contrast, the professionalisation strategy adopted by the statutory social work agency reflects the drivers of public service performance, fiscal and risk management imperatives. Employing Foucault's construct of governmentality, Randal concludes that government holds a dominant position over the profession in providing public accountability for social work practice and that this poses a risk that the professional body, the Aotearoa New Zealand Association of Social Workers will be left in its wake.

Evidence is mounting that poverty and psychological stress among university students is common and the mental health of university students is a topic of increasing attention. Susan Gair and Len Baglow recruited 2,320 social work students from 29 Australian universities to complete an online survey on the impact of low income on students' daily lives and study success. Overall, their findings reveal financial hardships and a precarious balancing act between study, limited finances, paid work and family with some impacts on mental health and wellbeing. This study has implications for universities, social work education, field placement preparation and the health of the social work graduate workforce within, and beyond Australia and it would be timely for a similar study to be carried out in Aotearoa.

\section{References}

Beddoe, L., \& Maidment, J. (2009). Mapping knowledge for social work practice: Critical intersections. Melbourne, VIC: Cengage.

Beddoe, L., \& Joy, E. (2017). Questioning the uncritical acceptance of neuroscience in child and family policy and practice: A review of challenges to the current doxa. Aotearoa New Zealand Social Work, 29(1), 65-76. doi:http://dx.doi.org/10.11157/anzswj-vol29iss1id213

Briskman, L. (2017). Revitalising radical social work. Aotearoa New Zealand Social Work, 29(2), 133-136. doi:10.11157/anzswj-vol29iss2id405

Blumhardt, H., Fourth World UK, A., \& Gupta, A. (2017). Radical practice in a risk-averse environment: Learning from ATD Fourth World UK. Aotearoa New Zealand Social Work, 29(2), 19-33. doi:10.11157/anzswj-vol29iss2id288

Booysen, P., \& Staniforth, B. (2017). Counselling in social work: A legitimate role? Aotearoa New Zealand Social Work 29(1), 16-27. doi:10.11157/anzswjvol29iss1id214

Chinnery, S.-A. (2016). Social work's fingerprint on the evolution of attachment theory: Some essential knowledge for care practice. Aotearoa New Zealand Social Work, 28(3), 79-90. doi:10.11157/anzswj-vol28iss3id216

Crawford, H. S. (2016). A Pākehā journey towards bicultural practice through guilt, shame, identity and hope. Aotearoa New Zealand Social Work, 28(4), 80-88. doi:10.11157/anzswj-vol28iss4id300

Fraser, H., Taylor, N., \& Signal, T. (2017). Young people empathising with other animals: reflections on an Australian RSPCA Humane Education Program. Aotearoa New Zealand Social Work, 29(3), 5-16. doi:10.11157/anzswj-vol29iss3id384

Giles, R. (2016). Social workers' perceptions of multidisciplinary team work: A case study of health social workers at a major regional hospital in New Zealand. Aotearoa New Zealand Social Work, 28(1), 25-33. doi:10.11157/anzswj-vol28iss1id113

Hobbs, E. K., \& Evans, N. (2017). Social work perceptions and identity: How social workers perceive public and professional attitudes towards their vocation and discipline. Aotearoa New Zealand Social Work, 29(4), 19-31. doi:10.11157/anzswj-vol29iss4id378

Hunt, S. (2016). The social work professionalisation project before the 1990s in Aotearoa New Zealand: The dream. Aotearoa New Zealand Social Work, 28(3), 15-25. doi:10.11157/anzswj-vol28iss3id245

Hunt, S. (2017). The social work regulation project in Aotearoa New Zealand. Aotearoa New Zealand Social Work, 29(1), 53-64. doi:10.11157/anzswj-vol29iss1id370

Hyslop, I. K. (2016). Where to social work in a brave new neoliberal Aotearoa? Aotearoa New Zealand Social Work, 28(1), 5-12. doi:10.11157/anzswj-vol28iss1id111

Jarldorn, M. (2016). Picturing creative approaches to social work research: Using photography to promote social change. Aotearoa New Zealand Social Work, 28(4), 5-16. doi:10.11157/anzswj-vol28iss4id293 
Keddell, E. (2016). Child protection reform and welfare reform in Aotearoa New Zealand: Two sides of the same coin? In J. Maidment \& L. Beddoe (Eds.), Social policy for social work and human services in Aotearoa New Zealand (pp. 237-251). Christchurch, NZ: Canterbury University Press.

Keddell, E., \& Hyslop, I. (2018). Role type, risk perceptions and judgements in child welfare: A mixed methods vignette study. Children and Youth Services Review, 87, 130-139. doi: https://doi.org/10.1016/j. childyouth.2018.02.017

New Zealand Productivity Commission. (2015). More effective social services: Summary version. Retrieved from: http://www.productivity.govt.nz/inquirycontent/2032? stage $=4$

O'Brien, M. (2016). The triplets: Investment in outcomes for the vulnerable - reshaping social services for (some) New Zealand children. Aotearoa New Zealand Social Work, 28(2), 1-6. doi:10.11157/anzswj-vol28iss2id220

Rogowski, S. (2017). Radical social work by Roy Bailey and Mike Brake: A classic text revisited. Aotearoa New Zealand Social Work, 29(4), 97-101. doi:10.11157/ anzswj-vol29iss4id463

Russell, A. (2017). Competent solidarity: The alternative for professional social work. Aotearoa New Zealand Social Work, 29(2), 137-143. doi:10.11157/anzswjvol29iss2id406

Sawyers, L. (2016). Finally accountable? Social work and the community investment strategy. Aotearoa New Zealand Social Work, 28(2), 32-39. doi:10.11157/anzswjvol28iss2id222

Stanfield, D., Beddoe, L., Ballantyne, N., Lowe, S., \& Renata, N (2017). Critical conversations: Social workers' perceptions of the use of a closed Facebook group as a participatory professional space. Aotearoa New Zealand Social Work, 29(3), 42-54. doi:10.11157/anzswj-vol29iss3id311

\section{Ian Hyslop, Kathryn Hay and Liz Beddoe}

